\title{
INFLUÊNCIA DA COBERTURA E DO SOMBREAMENTO DO CANTEIRO NA GERMINAÇÃO E DESENVOLVIMENTO INICIAL DE PLÂNTULAS DE PAU ROSA (Aniba rosaeodora)
}

\author{
Anibal da S. J. MARQUES', Vânia P. VARELA², Zilvanda L. de O. MELO ${ }^{2}$
}

RESUMO - Um experimento foi instalado no viveiro da Reserva Florestal Adolfo Ducke, Manaus, Amazonas, Brasil, com o objetivo de comparar três tipos de cobertura de canteiros empregados em viveiros florestais e testar quatro niveis de sombreamento na germinação, emergência e desenvolvimento de plântulas de pau rosa (Aniba rosaeodora Ducke). Na cobertura dos canteiros utilizou-se palha de arroz, serragem e vermiculita. Os niveis de sombreamento de 30,50 e $70 \%$ foram obtidos por meio de telas de poliolefinas de cor preta, sendo o de $0 \%$ obtido por semeadura a pleno sol. O delineamento estatístico foi de parcelas subdivididas em blocos ao acaso. Os tipos de cobertura utilizados e a interação entre os niveis de sombreamento e tipo de cobertura de canteiros nào influenciaram na germinação das sementes e no indice de velocidade de emergência. Os niveis de sombreamento não influenciaram na germinação das sementes, mas apresentaram efeito significativo no indice de velocidade de emergência. Os tipos de cobertura dos canteiros não influenciaram no desenvolvimento das plântulas em altura, diâmetro à altura do colo e peso da matéria seca da parte aérea, do sistema radicular e total; a área foliar das plântulas obtidas com a cobertura de vermiculita foi melhor que com serragem. Melhores resultados de crescimento em altura e peso da matéria seca da parte aérea, do sistema radicular e total, foram observados nas plântulas cultivadas sob os niveis de 30 e $50 \%$ de sombreamento. As interações de $30 \%$ de sombreamento com a cobertura de vermiculita e $50 \%$ de sombreamento com a cobertura de palha de arroz proporcionaram maiores valores de crescimento em altura e peso da matéria seca total das plântulas de pau rosa, respectivamente.

Palavras-chave: Produção de mudas, viveiro florestal, crescimento, emergência.

\section{Influence of Seedbed Mulching and Shading on the Germination and Early Development of Rosewood (Aniba rosaeodora) Seedlings.}

SUMARY - An experiment was carried out in the nursery at Adolph Ducke Forest Reserve, Manaus, Amazonas, Brazil, to compare three types of mulching material often used in forest nurseries and to test four shade levels on germination, emergence and development of rosewood (Aniba rosaeodora Ducke) seedlings. The seedbeds were covered with rice straw, sawdust and vermiculite. The shade levels $(30,50$ and $70 \%)$ were obtained by using black polyolefine screens and $0 \%$ shading intensity was obtained under full open sky. The experimental design was a split-plot in randomized blocks. The types of mulch and interaction between shading levels and mulching did not influence seed germination and emergence speed index. The shade levels did not influence seed germination, but significantly effected emergence speed index. The mulches did not influence seedling growth in height, diameter and shoot, root and total dry weight, but the leaf area of the seedlings obtained with vermiculite mulch was greater than that obtained with sawdust. Better results in height growth and shoot, root and total dry weight were observed in seedlings grown under 30 and $50 \%$ shade. The interactions between $30 \%$ shade and vermiculite mulching and $50 \%$ shade and rice straw provided the best height growth and total dry weight, respectively.

Key words: Seedling production, forest nursery, growth, emergence.

I Rua U, 12, conj. Eldorado, CEP 69.050-340, Manaus, AM, Brasil. E-mail: anibalMarques@hat mail.com

2 Instituto Nacional de Pesquisas da Amazônia (INPA). Cx. Postal 478, CEP 69.083-000, Manaus, AM, Brasil. 


\section{INTRODUÇÃO}

As explorações florestais na Amazônia iniciaram-se há mais de três séculos segundo o modelo extrativista, ou seja, a mera colheita seletiva de produtos naturais como a borracha, a castanha, os óleos vegetais, os óleos essenciais e a madeira, dentre outros. Dentre as espécies florestais com grande valor econômico destaca-se o pau rosa (Aniba rosaeodora Ducke), da familia Lauraceae, fonte do linalol, procurado no mercado nacional e internacional pelo seu uso como fixador em perfumaria. Como consequência, esta essência tem sido alvo do extrativismo desenfreado e está em vias de ser exterminada, uma vez que nenhuma providência foi tomada para impedir esse extrativismo nem para formação de novos povoamentos (Vieira, 1970).

Em programas de produção de mudas visando a formação de maçiços florestais puros ou mistos, há necessidade de uma série de cuidados que dependem do conhecimento prévio de suas caracteristicas fisiológicas e exigências ecológicas nas diversas etapas de seu ciclo vital. Portanto, estudos ecofisiológicos que identificam a influência de fatores ambientais na sobrevivência e desenvolvimento de espécies florestais tornam-se fundamentais. Entre os fatores controláveis são o sombreamento e a umidade do substrato.

Poggiani et al. (1992) estudaram o efeito do sombreamento sobre o crescimento das mudas de Angico branco (Piptadenia rigida) e observaram incremento significativo no peso de matéria seca das folhas e na área foliar quando exposta a $80 \%$ de sombra. Sturion (1980) trabalhou com mudas de Prunus brasiliensis e observou que as maiores taxas de sobrevivência e crescimento em altura foram obtidas quando conduzidas sob 30 e $60 \%$ de sombreamento. Observou, também, maior diâmetro do colo, maior peso da matéria seca do sistema radicular e da parte aérea nas mudas conduzidas a céu aberto ( $0 \%$ de sombreamento). Façanha \& Varela (1987) comprovaram que para a produção de mudas de Muirapiranga (Eperua bijuga) os niveis de sombreamento testados $(0 \%, 30 \%$ e $50 \%)$ não influenciaram no crescimento em altura, diâmetro à altura do colo e no peso da matéria seca da parte aérea e do sistema radicular. Para a espécie Louro pirarucu (Licaria canella), os maiores valores de peso da matéria seca da parte aérea e do sistema radicular foram obtidos sob $50 \%$ de sombreamento (Pinto et al.,1993). Esses autores verificaram ainda que a altura, área foliar e razão de área foliar nâo foram influenciadas pelos níveis de sombreamento.

Um outro fator importante na produção de mudas de espécies florestais é o tipo de cobertura utilizado sobre as sementes nos canteiros. O material usado deve proporcionar a umidade ideal à germinação e garantir a profundidade de semeadura, a nível tal que impeça o aparecimento das sementes à superfície dos canteiros e não dificulte a emergência das mesmas (Silva et al.,1980). Sturion (1980), trabalhando com mudas de Prunus brasiliensis, observou maior crescimento em 
diâmetro à altura do colo e peso da matéria seca do sistema radicular e da parte aérea das mudas cultivadas em canteiros cobertos com palha de arroz, em relação as cobertas com sepilho e serragem. Passos \& Ferreira (1991) mostram que o capim seco picado como cobertura de semeio foi o melhor tratamento para Algaroba (Prosopis juliflora).

$\mathrm{Na}$ literatura consultada não existe informação sobre métodos de produção de mudas de pau rosa (Aniba rosaeodora Ducke) e estas informações são fundamentais para permitir a sua utilização, com segurança, na formação de povoamentos florestais. Este trabalho tem como objetivo identificar o melhor tipo de cobertura do canteiro e analisar a influência de diferentes niveis de sombreamento sobre a germinação e desenvolvimento de plântulas de pau rosa.

\section{MATERIAL E MÉTODOS}

As sementes foram coletadas na Reserva Florestal Adolfo Ducke, Km 26 da rodovia Manaus - Itacoatiara (AM010), (latitude $03^{\circ} 00^{\prime} 00^{\prime \prime}$ e $03^{\circ} 08^{\prime} 00^{\prime \prime} \mathrm{S}$ e longitude $59^{\circ} 52^{\prime} 40^{\prime \prime}$ e $59^{\circ} 58^{\prime} 00^{\prime \prime}$ W) de um plantio com 28 anos de idade. As sementes foram homogeneizadas antes da realização do experimento instalado no viveiro desta reserva.

$\mathrm{O}$ clima da região é do tipo $\mathrm{Am}$, com temperatura média anual de $26,7^{\circ}$ C; a temperatura média de setembro, o mês mais quente, é de $27,9^{\circ} \mathrm{C}$ e em fevereiro ocorre a menor temperatura $25,8^{\circ} \mathrm{C}$. O regime pluviométrico define duas estações: uma seca e a outra chuvosa. A precipitação média anual é de $2.186 \mathrm{~mm}$, sendo os meses de julho a setembro os mais secos, cerca de 100 $\mathrm{mm} / \mathrm{mês}$, e os mais chuvosos, os meses de março e abril, com 300 mm/ mês (Lovejoy \& Bierregaard, 1990; Salati et al., 1991).

A semeadura em canteiros foi realizada dez dias após a coleta, utilizando-se como substrato uma mistura de areia e barro na proporção de 2:1. Utilizou-se palha de arroz, serragem e vermiculita para cobrir os canteiros. Foram utilizados quatro níveis de sombreamento; os niveis de 30,50 e $70 \%$ foram obtidos por meio de telas de poliolefinas de cor preta, com diferentes graus de sombra que recobriam as armações de madeira, partes lateral e superior, e o nivel de $0 \%$ foi obtido por semeadura a pleno sol.

O delineamento experimental foi de parcelas subdivididas em blocos casualizados; as parcelas foram constituidas pelos niveis de sombreamento e as subparcelas pelos tipos de cobertura, com quatro repetições. Foram utilizadas 25 sementes por subparcela, e as médias foram comparadas pelo teste de Tukey, ao nivel de $5 \%$ de probabilidade.

A contagem das sementes emergidas foi realizada diariamente por um periodo de 123 dias após a semeadura. Considerouse como sementes germinadas aquelas que apresentaram formação do caulículo sobre a superfície do substrato. Para fins de análise estatística, os dados de percentagem de germinação foram transformados em $\operatorname{arcsen} \sqrt{\mathbf{X} / 100}$ (Steel \& Torrie, 1960).

Com os resultados diários das sementes germinadas, foi calculado o Índice de Velocidade de Emergência (I.V.E.), conforme Maguire (1962): 


$$
\text { I. } V \cdot E_{0}=\frac{N 1}{D 1}+\frac{N 2}{D 2}+\cdots \cdots+\frac{N n}{D n}
$$

onde: $N_{1}=$ número de sementes germinadas no $1^{\circ}$ dia de contagem, $N_{2}$ $=$ número de sementes germinadas no $2^{\circ}$ dia de contagem, $N_{n}=$ número de sementes germinadas no enézimo dia de contagem, $D_{1}=$ números de dias após semeadura para $1^{\text {a }}$ contagem, $D_{2}=$ números de dias após semeadura para $2^{\mathrm{a}}$ contagem, $D_{\mathrm{n}}=$ números de dias após semeadura para enézima contagem.

Os parâmetros de crescimento foram avaliados aos 150 dias após a semeadura, com base na média de seis plântulas, tomadas ao acaso, por subparcela:

Altura total (cm) - desde o colo até a inserção da última folha;

Diâmetro à altura do colo (mm);

Área foliar $\left(\mathrm{cm}^{2}\right)$ - avaliada por meio de um medidor de área foliar portátil LI-COR Mod. LI 3000A;

Peso da matéria seca (g) da parte aérea, sistema radicular e total - as mudas foram seccionadas à altura do colo em duas partes (aérea e radicular) e postas para secar em estufa a $75^{\circ} \mathrm{C}$ com circulação forçada de ar até atingirem o peso constante.

\section{RESULTADOS E DISCUSSÃO}

A germinação e o I.V.E. não foram influenciados significativamente pelos tipos de cobertura utilizados (Tab.1). Silva et al. (1980) constataram que a cobertura de palha de arroz e serragem favorecem a germinação de sementes de Angico (Anadenanthera macrocarpa), a cobertura de palha de arroz foi melhor para germinação de sementes de Aroeira (Astronium urundeuva), e não houve diferença significativa entre os tratamentos na germinação de sementes de Canafistula (Cassia excelsa) e Sabiá (Mimosa caesalpinipholia). Silva et al. (1980) verificaram melhores resultados, tanto na germinação quanto no índice de velocidade de germinação (I.V.G.) das sementes de Eucalyptus citriodora com a utilização da casca de arroz, areia, carvão e vermiculita. Passos \& Ferreira (1991) mostraram que a maior percentagem de germinação de sementes de Algaroba (Prosopis juliflora) foi obtida utilizando-se areia lavada como cobertura no semeio e observaram que o tratamento onde utilizou-se a serragem como cobertura apresentou resultado idêntico ao obtido com a testemunha. Embora as coberturas usadas sobre as sementes de pau rosa tenham por finalidade minimizar os fatores que prejudicam a germinação, no presente estudo as coberturas testadas não foram eficientes ao ponto de resultar em diferenças nos resultados de germinação.

Tabela 1. Médias de percentagem de germinação das sementes de pau rosa (Aniba rosaeodora) e indice de velocidade de emergência (I.V.E.) em função de três tipos de cobertura de canteiro.

\begin{tabular}{lcc}
\hline Cobertura & Germinação (\%) & I.V.E. \\
\hline Palha de arroz & 42 & 0,18 \\
Serragem & 37 & 0,18 \\
Vermiculita & 41 & 0,20 \\
\hline F & $1,02^{\text {ns }}$ & $0,94^{\text {ns }}$ \\
CV $(\%)$ & 15,8 & 25,8 \\
\hline
\end{tabular}

ns - Não significativo pelo Teste $\mathrm{F}$ ao nivel de $5 \%$ de probabilidade

$\mathrm{F}$ e CV baseados na análise com dados transformados 
Não houve diferença significativa entre os tipos de sómbreamento e a interação entre niveis de sombreamento e tipos de cobertura de canteiros na germinação das sementes de pau rosa (Tab. 2). Resultados semelhantes foram obtidos por Gomes et al. (1978) na germinação de sementes de Eucalyptus grandis, e por Façanha \& Varela (1987) na germinação das sementes de Muirapiranga (Eperua bijuga). Algumas espécies florestais tem sido estudadas quanto às exigências de luz e mostraram comportamentos variados. A germinação de alguns tipos de sementes é inibida pela exposição a luz, enquanto que a de outros tipos é estimulada. Para a espécie em estudo, os niveis de sombreamento não favoreceram a germinação das sementes, o que demostra que são indiferentes à luz pelo menos quando a avaliação é feita em condições de viveiro.

Houve diferença significativa entre os niveis de sombreamento testados em relação ao I.V.E. (Tab. 2). Os niveis de sombreamento de 30,50 e $70 \%$ foram estatisticamente semelhantes entre si e superiores ao obtido com $0 \%$ de sombreamento, havendo uma emergência mais lenta das plântulas quando as sementes de pau rosa foram semeadas a pleno sol. Não houve diferença significativa na interação entre niveis de sombreamento e tipos de cobertura de canteiros.

Não ocorreu diferença significativa entre as coberturas no crescimento em altura, diâmetro à altura do colo e peso de matéria seca da parte aérea, do sistema radicular e total (Tab. 3). Entretanto, plântulas oriundas de sementes cobertas com serragem apresentaram menor
Tabela 2. Médias de percentagem de germinação das sementes de pau rosa (Aniba rosaeodora) e indice de velocidade de emergência (I.V.E.) em função de quatro niveis de sombreamento.

\begin{tabular}{lcc}
\hline Sombreamento & Germinaçăo (\%) & I.V.E. \\
\hline $0 \%$ & 35 & $0,12 \mathrm{~b}$ \\
$30 \%$ & 43 & $0,21 \mathrm{a}$ \\
$50 \%$ & 42 & $0,22 \mathrm{a}$ \\
$70 \%$ & 39 & $0,19 \mathrm{a}$ \\
\hline Fs & $1,68^{\text {ns }}$ & $9,63^{*}$ \\
FsC & $0,48^{\text {ns }}$ & $0,90^{\text {ns }}$ \\
CV (\%) & 14,4 & 22,5 \\
\hline
\end{tabular}

ns - Não significativo pelo Teste $F$ ao nível e $5 \%$ de probabilidade

** Significativo pelo Teste F ao nivel de $1 \%$ de probabilidade

Médias seguidas da mesma letra não diferem estatisticamente entre si, ao nivel de $5 \%$ de probabilidade, pelo teste de Tukey,

Fs, Fsc e CV baseados na análise com dados transformados

área foliar que as plântulas cujas sementes foram cobertas com vermiculita. O menor desenvolvimento da área foliar das plântulas produzidas com cobertura de serragem talvez possa ser justificado pela toxidez da cobertura que influenciou negativamente no desenvolvimento deste parâmetro. Deichmann (1967) também ressalta que o menor desenvolvimento possa ser causado pela toxidez do material e, quando entra em decomposição, as bactérias utilizam o nitrogênio do solo, reduzindo a disponibilidade desse elemento para as plantas. Passos \& Ferreira (1991) também constataram que a serragem teve efeito ligeiramente prejudicial sobre a altura das mudas de Algaroba (Prosopis juliflora). Sturion (1980) constatou que a palha de arroz é 
Tabela 3. Efeito de três tipos de cobertura de canteiros nas médias de altura (ALT), diâmetro à altura do colo (DIA), peso de matéria seca da parte aérea (PSPA), do sistema radicular (PSSR) e total (PST) e área foliar (AREFO) das plântulas de pau rosa (Aniba rosaeodora).

\begin{tabular}{lllllll}
\hline Cobertura & ALT & DIA & \multicolumn{2}{c}{ Matéria seca $(\mathrm{g})$} & & AREFO \\
\hline & $(\mathrm{cm})$ & $(\mathrm{mm})$ & PSPA & PSSR & PST & $\left(\mathrm{cm}^{2}\right)$ \\
Palha de arroz & 8,17 & 0,25 & 0,34 & 0,17 & 0,51 & $28,66 \mathrm{ab}$ \\
Serragem & 8,78 & 0,25 & 0,34 & 0,17 & 0,51 & $26,35 \mathrm{~b}$ \\
Vermiculita & 8,86 & 0,27 & 0,39 & 0,20 & 0,56 & $33,42 \mathrm{a}$ \\
\hline F & $2,56^{\text {ns }}$ & $1,52^{\text {ns }}$ & $2,00^{\text {ns }}$ & $1,77^{\text {ns }}$ & $0,85^{\text {ns }}$ & $3,85^{\circ}$ \\
CV $(\%)$ & 10,6 & 4,6 & 25,3 & 26,3 & 23,5 & 25,0 \\
\hline
\end{tabular}

ns - Năo significativo pelo Teste $\mathrm{F}$ ao nível de $5 \%$ de probabilidade

* Significativo pelo Teste $\mathrm{F}$ ao nível de $5 \%$ de probabilidade

Médias seguidas da mesma letra não diferem estatisticamente entre si, ao nível de $5 \%$ de probabilidade, pelo teste de Tukey.

o tipo de cobertura de canteiro mais indicado para se obter maior crescimento em altura, diâmetro à altura do colo e maior peso da matéria seca do sistema radicular e da parte aérea das mudas de Prunus brasiliensis, provavelmente devido à maior retenção de umidade no substrato.

Não foram encontradas diferenças significativas na altura das plântulas entre os niveis de sombreamento de 30,50 e $70 \%$, embora os niveis 30 e $50 \%$ fossem estatisticamente superiores ao pleno sol (Tab. 4). Maior desenvolvimento em altura foi observado por Sturion (1980) nas mudas de Prunus brasiliensis produzidas sob 30 e $60 \%$ de sombreamento versus sem sombreamento. Pedroso \& Varela (1995) não observaram diferenças significativas na altura entre os niveis de sombreamento para mudas de Sumaúma (Ceiba pentandra).

Houve interação entre niveis de sombreamento e tipos de cobertura de canteiros, ao nivel de $5 \%$ de probabilidade, na altura e no peso da matéria seca total das plântulas de pau rosa (Tab. 4).
Observou-se que o tratamento com cobertura de vermiculita e sombreamento de $30 \%$ apresentou resultado superior quando comparado aos demais tipos de cobertura neste nivel de sombreamento, embora o melhor resultado de altura tivesse sido observado com a cobertura de palha de arroz associada ao nivel de $50 \%$ de sombreamento. A cobertura de serragem manteve médias de altura similares nos quatro níveis de sombreamento (Fig. 1).

Observou-se que a cobertura de palha de arroz associada a $50 \%$ de sombreamento apresentou melhor resultado em termos de matéria seca total (Fig. 2), ocorrendo um decréscimo acentuado quando esse tipo de cobertura foi associado a $70 \%$ de sombreamento. $\mathrm{O}$ melhor resultado com a cobertura de vermiculita foi alcançado com $30 \%$ de sombreamento. Os maiores valores de peso de matéria seca total obtidos com as plântulas de pau rosa cobertas com palha de arroz e vermiculita em sombreamentos intermediários podem ser explicados pela maior retenção de umidade no substrato, proporcionado pelas 
Tabela 4. Efeito de quatro níveis de sombreamento nas médias de altura (ALT), diâmetro do colo (DIA), peso de matéria seca da parte aérea (PSPA), do sistema radicular (PSSR) e total (PST) e área foliar (AREFO) das plântulas de pau rosa (Aniba rosaeodora)

\begin{tabular}{lllllll}
\hline Sombreamento & ALT & DIA & \multicolumn{2}{l}{ Matéria seca $(\mathrm{g})$} & & AREFO \\
\hline & $(\mathrm{cm})$ & $(\mathrm{mm})$ & PSPA & PSSR & PST & $\left(\mathrm{cm}^{2}\right)$ \\
\hline $0 \%$ & $7,50 \mathrm{~b}$ & 0,25 & $0,29 \mathrm{~b}$ & $0,14 \mathrm{~b}$ & $0,38 \mathrm{~b}$ & $25,82 \mathrm{ab}$ \\
$30 \%$ & $9,03 \mathrm{a}$ & 0,28 & $0,42 \mathrm{a}$ & $0,21 \mathrm{a}$ & $0,63 \mathrm{a}$ & $34,07 \mathrm{a}$ \\
$50 \%$ & $9,39 \mathrm{a}$ & 0,27 & $0,41 \mathrm{a}$ & $0,21 \mathrm{a}$ & $0,63 \mathrm{a}$ & $32,65 \mathrm{ab}$ \\
$70 \%$ & $8,48 \mathrm{ab}$ & 0,24 & $0,30 \mathrm{~b}$ & $0,15 \mathrm{~b}$ & $0,45 \mathrm{~b}$ & $25,37 \mathrm{~b}$ \\
\hline Fs & $9,21^{*}$ & $2,41^{\text {ns }}$ & $7,14^{* *}$ & $8,40^{*}$ & $12,15^{*}$ & $4,54^{*}$ \\
Fsc & $2,80^{*}$ & $1,52^{\text {ns }}$ & $2,21^{\text {ns }}$ & $1,44^{\text {ns }}$ & $2,63^{*}$ & $1,38^{\text {ns }}$ \\
CV $(\%)$ & 14,8 & 14,0 & 30,8 & 35,6 & 23,8 & 29,3 \\
\hline
\end{tabular}

ns - Não significativo pelo Teste $\mathrm{F}$ ao nível de $5 \%$ de probabilidade

* Significativo pelo Teste. $\mathrm{F}$ ao nível de $5 \%$ de probabilidade

** Significativo pelo Teste $\mathrm{F}$ ao nível de $1 \%$ de probabilidade

Médias seguidas da mesma letra não diferem estatisticamente entre si, ao nível de $5 \%$ de probabilidade, pelo teste de Tukey.

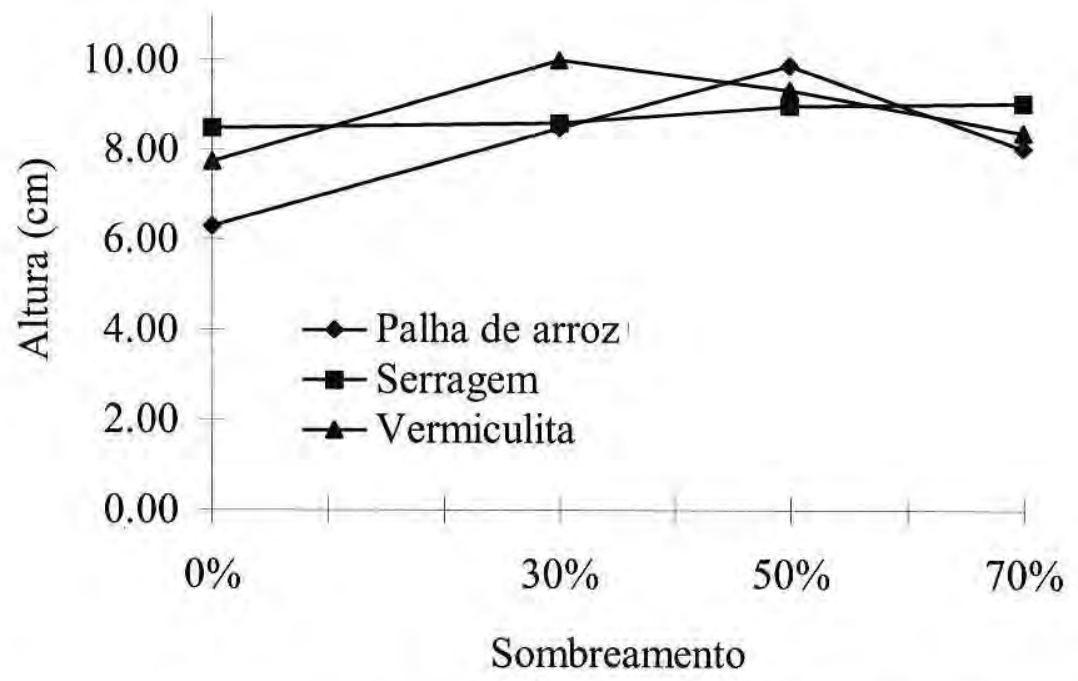

Figura 1. Médias de altura das mudas de pau rosa (Aniba rosaeodora) em função de quatro niveis de sombreamento e três tipos de cobertura dos canteiros. 
coberturas e pelo fato desta espécie na fase juvenil apresentar-se como tolerante a sombra, capaz de acumular maior taxa de crescimento nestes niveis.

Não houve diferença significativa entre o diâmetro do colo das plântulas de pau rosa produzidas sob $0,30,50$ e $70 \%$ de sombreamento (Tab. 4). Estudos recentes realizados com outras espécies arbóreas têm demostrado que na fase juvenil a taxa de crescimento em diâmetro pode ser ou não favorecida pelo sombreamento. Mudas de Amburana cearensis (Engel, 1989), por exemplo, apresentaram maior taxa de crescimento em diâmetro sob níveis de sombra mais intensos (41 a $82 \%$ de sombreamento). Varela \& Santos (1992) observaram decréscimo no diâmetro do colo das mudas de Angelim pedra (Dinizia excelsa) com o sombreamento.

O sombreamento intermediário proporcionou maior acúmulo de peso de matéria seca da parte aérea, do sistema radicular e total das plântulas de pau rosa, quando comparados com os níveis de 0 e $70 \%$. Varela \& Santos (1992) também observaram que as mudas de Angelim pedra (Dinizia excelsa) produzidas sob 30 e $50 \%$ de sombreamento apresentaram peso de matéria seca da parte aérea e do sistema radicular superiores àquelas produzidas sob $70 \%$.

A medida que diminui a intensidade luminosa, há redução na produção de matéria seca, pois o hidrato de carbono é mais consumido pela respiração do que pela fotossintese. Plântulas com menores valores de peso de matéria seca total também foram obtidas quando cultivadas sob $0 \%$ de sombreamento. Estas duas situações observadas

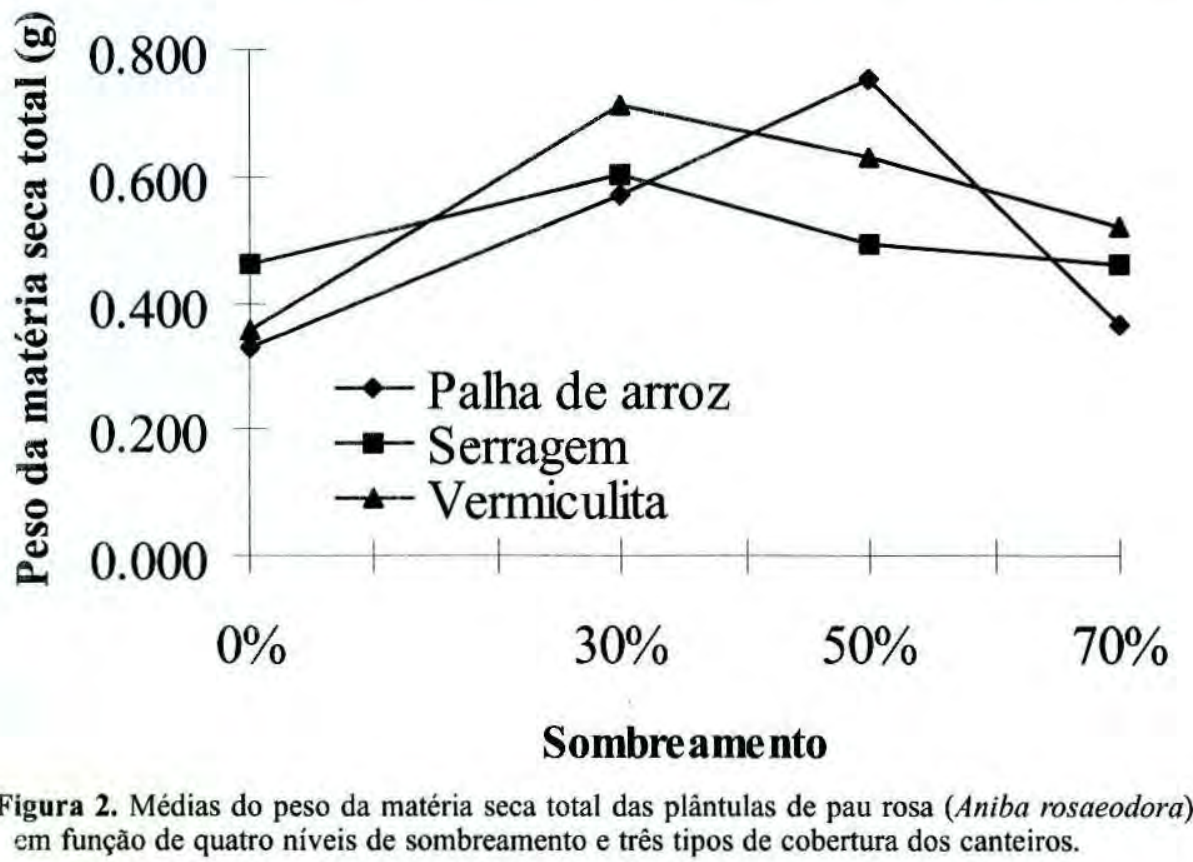


reforçam a hipótese de que as plântulas de pau rosa apresentam comportamento intermediário do ponto de vista adaptativo, respondendo preferencialmente a ambientes intermediários.

O nível de $30 \%$ foi superior ao $70 \%$ de sombreamento na área foliar das plântulas de pau rosa. Esse aumento da área foliar mostra a influência das folhas na captação de energia solar e produção de matéria orgânica, contribuindo, assim, para o crescimento das plântulas, tendo em vista que nesse mesmo nivel de sombreamento ocorreu um incremento de matéria seca da parte aérea, do sistema radicular e total. Pinto et al. (1993) observaram que não ocorreu diferença significativa na área foliar das mudas de Louro pirarucu (Licaria canella) cultivadas sob os níveis de sombreamento de $0,30,50$ e $70 \%$.

\section{CONCLUSÕES E SUGESTÕES}

Os tipos de cobertura utilizados e os níveis de sombreamentos testados não influenciaram a percentagem de germinação das sementes de pau rosa. No entanto, o nível de pleno sol reduziu $o$ indice de velocidade de emergência.

Melhor crescimento em altura e peso da matéria seca da parte aérea, do sistema radicular e total foi observado nas mudas de pau rosa cultivadas sob os niveis de 30 e $50 \%$ de sombreamento. Isto reforça a hipótese que esta espécie é preferencialmente de habitat intermediário, pelo menos a nível de viveiro.

As interações de $30 \%$ de sombreamento com cobertura de vermiculita e $50 \%$ de sombreamento com cobertura de palha de arroz proporcionaram maiores valores de altura e peso da matéria seca total das plântulas de pau rosa, respectivamente.

O comportamento favorável à sombra apresentado pelo pau rosa neste estudo sugere que para a produção de mudas utilize-se niveis de sombreamento de 30 ou $50 \%$, uma vez que maiores valores de peso de matéria seca total foram obtidos com as plântulas cobertas com palha de arroz e vermiculita em sombreamentos intermediários.

Com vistas à obter maiores informações relativas ao desenvolvimento das plântulas sob condições de viveiro, sugere-se novos estudos envolvendo um número maior de amostras que possibilitem avaliações periódicas dos parâmetros morfológicos e fisiológicos de crescimento, associadas a determinações bioquímicas ao longo do tempo, permitindo estabelecer inferências mais seguras sobre o comportamento da espécie.

\section{Bibliografia Citada}

Deichmann, V. von 1967. Noções sobre sementes e viveiros florestais. Escola de Floresta, Universidade Federal do Paraná, Curitiba. 196p.

Engel, V.L. 1989. Influência do sombreamento sobre o crescimento de mudas de essências florestais nativas, concentração de clorofila nas folhas e aspectos da anatomia. Dissertação de Mestrado, ESALQ/USP, Piracicaba. 202p.

Façanha, J.G.V.; Varela, V.P. 1987. Influência do tamanho da semente e tipo de sombreamento na produção de mudas de Muirapiranga. Pesq. Agrop. Bras., 22(11/12):1185-1188.

Gomes, J.M.; Ferreira, M.G.M.; Brandi, R.M.; Paula Neto, F. de. 1978. Influência do sombreamento no desenvolvimento de Eucalyptus grandis W. Hill. ex Maiden. Revista Árvore, 2(1):68-75. 
Lovejoy, T.E.; Bierregaard Jr, R.O. 1990. Central Amazonian forests and the minimum critical size of ecosystems projects. In: A. H. Gentry (Ed.). Four Neotropical Rainforests. Yale University Press, New Haven. p. 60-71.

Maguire, J.D. 1962. Speed of germinacion - aid in selection and evalution for seedling emergence and vigor. Crop Science, 2(2):176-177.

Passos, M.A.; Ferreira, R.L.C. 1991. Influência da cobertura de semeio na emergência e desenvolvimento inicial de Algaroba. Revista Brasileira de Sementes, 13(2):151-153.

Pedroso, S.G.; Varela, V.P. 1995. Efeito do sombreamento no crescimento de mudas de Sumaúma (Ceiba pentandra (L.) Gaertn.). Revista Brasileira de Sementes, 17(2):47-51.

Pinto, A.M.; Varela, V.P.; Batalha, L.F.P. 1993. Influência do sombreamento no desenvolvimento de mudas de Louro pirarucu (Licaria canella (Meissn.) Kosterm.). Acta Amazonica, 23(4):397-402.

Poggiani, F.; Bruni, S.; Barbosa, E.S.Q. 1992. Efeito do sombreamento sobre o crescimento das mudas de três espécies florestais. Revista do Instituto Florestal, 2:564-569

Salati, E.; Ribeiro, M.N.G.; Absy, M.L.; Nelson, B.W. 1991. Clima da Amazônia: presente, passado e futuro. In: Val, A.L.; Frigliolio, R.; Feldeberg, E. (Eds). Bases Cientificas para Estratégias de Preservação e Desenvolvimento da Amazônia: Fatos e Perspectivas. Vol.1. Instituto Nacional de Pesquisas da Amazônia (INPA), Manaus, Amazonas. p.21-36.
Silva, H.D. da; Souza, S.M. de; Ribaski, J. 1980. Efeito de diferentes tipos de cobertura na produção de mudas de algumas espécies florestais. Boletim dePesquisa, EMBRAPACPATSA, 2:31-39.

Steel, R.G.D.; Torrie, J.H. 1960. Principles and procedures of statistics. McGraw-Hill, London. 481p.

Sturion, J.A. 1980. A influencia da profundidade da semeadura, cobertura do canteiro e sombreamento na formação de mudas de Prunus brasiliensis Schott ex Spreng. Boletim de Pesquisa Florestal, 1:50-68.

Varela, V.P.; Santos, J. dos. 1992. Influência do sombreamento na produção de mudas de Angelim Pedra (Dinizia excelsa, Ducke). Acta Amazonica, 22(3):407-411.

Vieira, A.N. 1970. Aspectos silviculturais do Pau-rosa (Aniba duckei Kostermans). I. Estudos preliminares sobre o incremento volumétrico. Boletim do INPA, 14: 1-15. 